\title{
Modeling and Validation of an Electric Arc Furnace: Part 1, Heat and Mass Transfer
}

\author{
Vito LOGAR, Dejan DOVŽAN and Igor ŠKRJANC
}

Laboratory of modeling, simulation and control, Faculty of Electrical Engineering, University of Ljubljana, Tržaška 25, SI-1000 Ljubljana.E-mail: vito.logar@fe.uni-lj.si,dejan.dovzan@fe.uni-lj.si, igor.skrjanc@fe.uni-lj.si

(Received on September 2, 2011; accepted on October 11, 2011)

\begin{abstract}
The following paper presents an approach to the mathematical modeling of heat and mass transfer processes in a 3-phase, 80 MVA AC, electric arc furnace (EAF) and represents a continuation of our work on modeling the electric and hydraulic EAF processes. This paper represents part 1 of the complete model and addresses issues on modeling the mass, temperature and energy processes in the EAF, while part 2 of the paper focuses solely on the issues related to the thermo-chemical relations and reactions in the EAF. As is generally known, the chemical, thermal and mass processes in an EAF are related to each other and cannot be studied completely separately; therefore, the work presented in part 1 and part 2 is related to each other accordingly and should be considered as a whole. The presented sub-models were obtained in accordance with different mathematical and thermo-dynamic laws, with the parameters fitted both experimentally, using the measured operational data of an EAF during different periods of the melting process, and theoretically, using the conclusions of different studies involved in EAF modeling. In conjunction with the already presented electrical and hydraulic models of the EAF, the heat-, mass- and energy-transfer models proposed in this work represent a complete EAF model, which can be further used for the initial aims of our study, i.e., optimization of the energy consumption and development of the operator-training simulator. The presented results show high levels of similarity with both the measured operational data and the theoretical data available in different EAF studies, from which we can conclude that the presented EAF model is developed in accordance with both fundamental laws of thermodynamics and the practical aspects regarding EAF operation.
\end{abstract}

KEY WORDS: EAF; heat-transfer model; mass-transfer model; experimental validation.

\section{Introduction}

The paper proposes an approach to the mathematical modeling of heat and mass transfer processes in an $80 \mathrm{MVA}$ $\mathrm{AC}$, electric arc furnace (EAF) and represents the continuation of our work on modeling the electrical and hydraulic EAF processes. ${ }^{1)}$ The relations and sub-models studied in this paper are considered as part 1 of the complete EAF model, with the thermo-chemical relations in the EAF being addressed in part 2. As is generally known, the chemical, thermal and mass processes in an EAF are related to each other and cannot be considered separately; therefore, the work presented in part 1 and part 2 is related to each other accordingly and should be considered as a whole. The main objective of the models proposed in this paper is to obtain accurate and reliable relations that describe different types of heat and mass transfers between the EAF zones, i.e., the solid and liquid steel and slag zones, the gas zone, the EAF's roof and walls, etc. The thermal processes considered in this paper include the heat transfer dissipated from the arcs, the radiative heat exchange, the view factors and temperature changes, while part 2 represents the chemical reactions and the corresponding thermal relations. As for the mass-transfer model, this paper presents mass-transfer models as a consequence of steel and slag melting, while additional mass transfers that occur as a consequence of chemical reactions are described in part 2. A reference to part 2 is added at each necessary point as (PART 2).

When examining the literature, some papers that propose different approaches to the modeling of the mass transfer and/or thermal processes in the EAF already exist, from simplified and more complex general heat- and mass-transfer models ${ }^{2,3)}$ to a more focused analysis of different heat submodels. ${ }^{4,5)}$ The idea of the model presented in this paper was derived from the papers of Bekker ${ }^{2}$ and MacRosty; ${ }^{3)}$ however, the model proposed by Bekker is oversimplified for the needs of our study, while the model proposed by MacRosty either describes differently or does not address some issues on the radiative and conductive heat transfer between the steel, the slag and the gas zones and the $C O$ postcombustion, which are in our opinion also important for the overall accuracy of the model. Therefore, a more complex model, taking into account additional relations and eliminating the deficiencies of the previously mentioned models is proposed in this study. Besides the modeling of the fundamental laws of mass and heat transfer, special attention is devoted to the parameterization of the developed model using available initial, endpoint and online measurements of the EAF's operation. As some relations in the EAF process are hard to be modeled mathematically, approximate equations are proposed to fit the obtained measurements.

Like the electrical model developed in our previous work, the model proposed here is based on the 80 MVA AC furnace installed in one of the ironworks in Slovenia. There- 
fore, for the needs of a successful model parameterization, the operational data of the EAF related to the heat- and mass-transfer processes was obtained, including the initial and endpoint steel and slag masses, the temperatures, the power-on times, the steel yields, the temperatures of the cooling panels, the energy consumption per baskets and heats, etc. Other measurements, such as the arc powers, which are needed to complement the proposed models, were already obtained when modeling the electrical processes in the EAF.

\section{Modeling}

The following section presents the approach to the modeling of heat- and mass-transfer processes for the particular EAF. The values of all the parameters used in the developed model are listed in the Appendix section.

\subsection{Modeling Assumptions and Simplifications}

As is generally known in modeling practice, the developed model should meet the initial design goals; however, for practical applications of the models several assumptions and simplifications are often needed in order to either achieve those goals, or to meet other requirements related to the model in general (stability, robustness, etc.). This is especially true for the electric arc furnace modeling, which combines different hydraulic, electrical, thermal, chemical and other processes. Therefore, to develop an applicable, robust and fairly accurate model, certain assumptions and simplifications need to be made, as some of the modeled processes cannot be completely described by conventional laws and include different forms of randomness. The assumptions and simplifications regarding the heat- and mass-transfer models proposed are:

- Due to the lack of some online measurements (mass balance, temperatures, etc.), the developed model, describing the related processes, should follow the fundamental (ideal) laws of heat and mass transfer, without considering the possible random processes, which cannot be modeled by conventional principles. The identifiable parameters of the model are determined using the initial and endpoint measurements of the process values, while the non-identifiable parameters are obtained from the conclusions of different practical studies, investigating heat and mass transfers.

- In order to combine the existing electrical and hydraulic models with the proposed model and to avoid possible numerical problems due to the stiffness of the combined model, the integration method should remain the same as for the electrical model, ${ }^{1)}$ i.e., fixed-step Euler, sample time $T_{s}=10^{-4} \mathrm{~s}$.

- Any occurring discontinuities that are necessary for the proper model response should be modeled in a manner that does not cause numerical and/or stability problems.

- The modeled EAF is divided into different zones, where the constituents of each zone possess similar or equal thermal, chemical and physical properties. Each zone is considered as homogenous, both in the constituent's properties, as in temperature levels, e.g., the temperature and composition of the steel scrap is considered equal throughout the solid-scrap zone, even though the actual EAF operation is far from this assumption. However, since the proposed model does not focus on the mass and heat transfers inside each zone, which would require a more complex 3-dimensional modeling, but rather concentrates on the zones as a whole, such an assumption seems reasonable.

Considering the above-mentioned assumptions and simplifications, the EAF layout is divided into different zones, intended for the mass- and heat-transfer models, as follows:

- solid scrap zone $(s S c)$, containing the elements such as: Fe, $\mathrm{Si}, \mathrm{Mn}, \mathrm{Cr}, \mathrm{C}$ and $\mathrm{P}$ in solid form,

- liquid scrap zone $(l S c)$, containing the same elements as the solid scrap zone, but in liquid form,

- solid slag zone $(s S l)$, containing charged slag-forming compounds such as: $\mathrm{CaO}, \mathrm{MgO}$ and $\mathrm{Al}_{2} \mathrm{O}_{3}$ in solid form,

- liquid slag zone $(l S l)$, containing the slag-forming and oxidation-process compounds in liquid form such as: $\mathrm{CaO}$, $\mathrm{MgO}, \mathrm{FeO}, \mathrm{SiO}_{2}, \mathrm{MnO}, \mathrm{Cr}_{2} \mathrm{O}_{3}, \mathrm{P}_{2} \mathrm{O}_{5}$ and $\mathrm{Al}_{2} \mathrm{O}_{3}$ in liquid form,

- gas zone (gas), containing the gases either lanced into the EAF or produced as a product of oxidation/reduction, such as: $\mathrm{N}_{2}, \mathrm{O}_{2}, \mathrm{CO}, \mathrm{CO}_{2}$ and $\mathrm{CH}_{4}$.

Two more EAF zones were added for the needs of the conductive and radiative heat-transfer model:

- roof zone,

- wall zone,

both primarily defined for computing the cooling powers and the EAF cooling losses. For the needs of the heat- and mass-transfer models, each zone is assigned common parameters describing its physical properties, i.e., specific heat $C_{p}$, density $\rho$, thermal conduction $k$, molar mass $M$, etc., which are the average values proportional to the physical properties of its constituents. The zones are schematically presented in Fig. 1.

\subsection{Heat Transfer Model}

When operating the EAF all three types of heat transfers, i.e., conductive, convective and radiative, are present. Heat conduction occurs between the zones in the furnace, which are in a direct contact with each other. Convection of the heat is present between the gas zone and the surrounding zones, while radiation prevails between the surfaces that are in the field of vision of each other. Considering all three mechanisms of heat transfer, the EAF thermal model is based on the heat-transfer or energy-balance equations, which are determined for each of the previously mentioned EAF zones.

\section{Solid scrap zone $(s S c)$}

The solid-scrap zone receives the heat from the arcs $Q_{\text {arc }}$, liquid metal $Q_{l S c-s S c}$, liquid slag $Q_{s S c-l S l}$, gas zone $Q_{s S c \text {-gas }}$, oxygen burners $Q_{\mathrm{CH} 4}{ }^{(\mathrm{PART} 2)}$ and CO post-combustion $Q_{\text {CO-post }}{ }^{\text {(PART 2); }}$; while its energy is exchanged with the solid slag $Q_{s S c-s S l}$ and lost to the water-cooled panels $Q_{s S c \text {-water }}$ Also, a large portion of the heat is exchanged through the radiation $Q_{s S c-R A D}$, which is dependent on the thermal conditions, emissivity coefficients, surface areas and view factors in the furnace, which are addressed in Section 2.2.1. The energy received from the oxygen burners, arcs and $\mathrm{CO}$ post-combustion is dependent on the exposure coefficient $K_{s S c-l S c}$ (Eq. (32)), which determines the fractions of the arc and burner energy transferred either to the solid or liquid metal zones. The

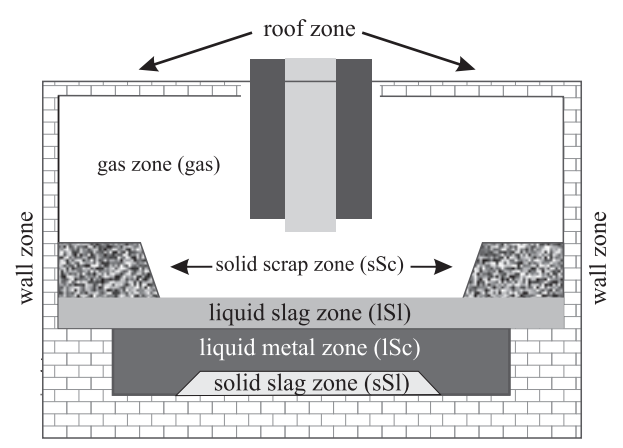

Fig. 1. Schematic representation of the EAF zones. 
energy balance for the solid steel zone can therefore be represented by Eq. (1):

$$
\begin{aligned}
& Q_{s S c}=\left(Q_{a r c}+Q_{C H_{4}}+K_{p o s t} Q_{C O-p o s t}\right) \cdot\left(1-K_{s S c-l S c}\right)+Q_{I S c-s S c} \\
& -Q_{s S c-s S l}-Q_{s S c-l S l}-Q_{s S c-\text { gas }}-Q_{s S c-\text { water }}-Q_{s S c-R A D},
\end{aligned}
$$

where $K_{\text {post }}$ denotes the efficiency of CO post-combustion. $\mathrm{CO}$ post-combustion energy, which is not reflected to the steel zone, is otherwise used to heat the gas zone. The negative sign preceding $Q_{S S c-R A D}$ denotes that the solid-scrap zone receives radiative energy.

The energy added to the solid steel zone from the arcs is directly dependent on the arc powers. As suggested, the arc energy transferred to the steel through conduction amounts to $15-20 \%$ of the total arc power, $75-85 \%$ of the arcs' energy is transferred to the furnace surfaces by radiation ${ }^{6)}$ and some of the energy is lost to gas and electrodes $(2-5 \%) ., 7)$ In our case the energy dissipated from the arcs by conduction $\left(Q_{a r c}\right)$ is proportional to arcs' powers and represents $20 \%$ of the total power, the energy transferred by radiation $\left(Q_{\text {arc-RAD }}\right)$ is assumed to represent $75 \%$ of arc power, $2.5 \%$ of the arc power heats the gas zone $\left(Q_{\text {arc-gas }}\right)$, while the remaining $2.5 \%$ of the energy is lost to electrodes and is thus neglected in further calculations. $Q_{\text {arc }}$ can therefore be defined by Eq. (2):

$$
Q_{\text {arc }}=0.20 \cdot P_{\text {arc }},
$$

where $P_{\text {arc }}$ represents the sum of arc powers. Radiative heat from the arcs is included in $Q_{S S c-R A D}$ and is addressed in Section 2.2.1.

The energy added to the solid steel zone from the oxygen burners $Q_{C H 4}$ is proportional to the burners' power and we suggest that their efficiency is described by the following Eq. (3):

$$
Q_{C_{4}}=\Delta H_{T-n}^{\circ} K_{\text {burn }} \cdot\left(0.35+0.65 \tanh \left(\frac{1300^{\circ} \mathrm{C}}{T_{s S c}}-1\right)\right), . .
$$

where $\Delta H_{T-n}^{\circ}{ }^{\text {(PART 2) }}$ represents the energy provided by the burners, $K_{\text {burn }}$ represents the approximate burner efficiency $(0.7)^{6)}$ and together with $\left(0.35+0.65 \tanh \left(\frac{1300^{\circ} \mathrm{C}}{T_{s}}-1\right)\right)$ represents the hyperbolic-tangent approximation which accounts for decreasing burner efficiency with increasing temperature of the steel. Hyperbolic-tangent burner efficiency approximation is derived from the paper of Bergman and Gottardi, ${ }^{8)}$ who suggest that the burner efficiency is decreasing proportionally to the $\%$ of the meltdown time. Since the current temperature of the steel is related to the \% of the meltdown time, we suggest that the burner efficiency is approximated by the temperature of the solid steel. The comparison between the measured ${ }^{8)}$ and the approximated burner efficiency can thus be represented by Fig. 2 .

Modern EAF assemblies use the advanced technology of carbon monoxide (CO) post-combustion. The idea of the post-combustion is to oxidize the carbon monoxide, which is produced by chemical reactions in the bath, to carbon dioxide $\left(\mathrm{CO}_{2}\right)$ and use the energy of the chemical reaction with oxygen, instead of emitting the $\mathrm{CO}$ to off-gas. The energy added to the solid steel zone from the CO postcombustion $Q_{\text {CO-post }}$ is dependent on the efficiency $\left(K_{\text {post }}\right)$ of the post-combustion and is discussed in part $2^{\text {(PART 2) }}$.

The energy flow between the solid and liquid scrap zones $Q_{l S c-s S c}$ can be described by Eq. (4) as follows:

$$
Q_{l S c-s S c}=m_{l S c-s S c} K_{\text {therm } 1} K_{\text {area } 1}\left(T_{l S c}-T_{s S c}\right) \text {, }
$$

where $m_{l S c-s S c}$ represents the mass of either the solid or liquid metal, depending on which one is smaller; $K_{\text {therm } 1}$ represents the heat-transfer coefficient; $K_{\text {areal }}$ represents the area coefficient between both zones; $T_{l S c}$ and $T_{S S c}$ represent the tem-

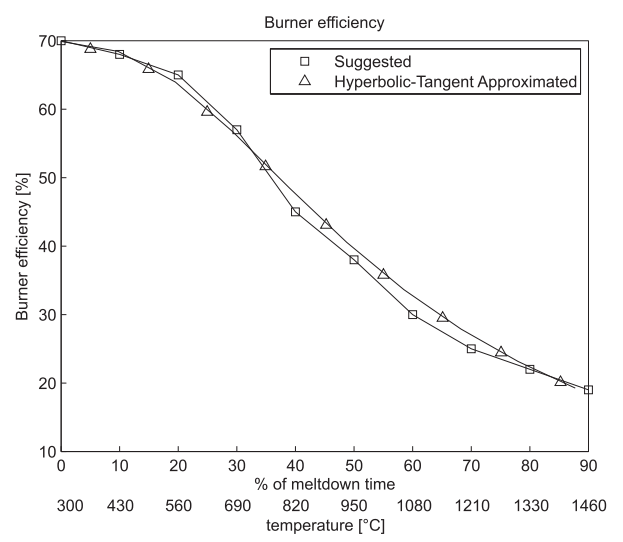

Fig. 2. Comparison between the measured (suggested) ${ }^{8)}$ and the tangent-hyperbolic approximated burner efficiency. X-axis label shows the percentage of the meltdown time as proposed by Ref. 8) and the corresponding temperature of solid steel as can be obtained from the model.

peratures of the solid and liquid metal zones, respectively.

Like Eq. (4), the energy exchange between the solid scrap, solid slag and liquid slag zones can be defined by Eqs. (5) and (6):

$$
\begin{aligned}
Q_{s S c-s S l} & =m_{s S c-s S l} K_{\text {therm } 2} K_{\text {area } 2}\left(T_{s S c}-T_{s S l}\right), \\
Q_{s S c-l S l} & =m_{s S c-l S l} K_{\text {therm } 3} K_{\text {area } 3}\left(T_{s S c}-T_{l S l}\right),
\end{aligned}
$$

where $m_{s S c-s S l}$ and $m_{s S c-l S l}$ represent the masses of either the solid steel or the solid or liquid slag, depending on which one is smaller; $K_{\text {therm } 2}$ and $K_{\text {therm } 3}$ represent the heat-transfer coefficients; $K_{\text {area } 2}$ and $K_{\text {area } 3}$ represent the area coefficients between the solid steel and the solid or liquid slag zones; $T_{S S c}, T_{s S l}$ and $T_{l S l}$ represent the temperatures of the solid steel and the solid and liquid slag zones, respectively.

The energy exchanged between the solid scrap and the surrounding gas $Q_{s S c \text {-gas }}$ can be described by Eq. (7) as follows:

$$
Q_{s S c-\text { gas }}=\frac{m_{s S c}}{m_{E A F}} K_{\text {therm } 4}\left(T_{s S c}-T_{\text {gas }}\right) \cdot\left(1-K_{s S c-l s c}\right),
$$

where $m_{S S c}$ represents the current mass of solid steel; $m_{E A F}$ represents the EAF mass capacity; $K_{\text {therm } 4}$ represents the thermal conductance coefficient; $T_{s S c}$ and $T_{\text {gas }}$ represent the temperatures of the solid steel and the gas zones, respectively; $K_{s S c-l s c}$ represents the exposure coefficient of the solid or liquid metal (Eq. (32)). Coefficient $K_{\text {therm } 4}$ was obtained from the approximate heat transfer coefficient for steel ${ }^{7,9,10)}$ taking into account the properties of the specific EAF. Together with fraction $\frac{m_{S S C}}{m_{F}}$ this factor accounts for decreasing heat transfer to the gas $\mathrm{Z}$ (one with decreasing mass of solid steel.

A portion of the solid steel energy is lost due to the cooling $\left(Q_{\text {sSc-water }}\right)$ of the furnace walls, which was modeled by Eq. (8):

$$
Q_{s S c-\text { water }}=K_{\text {water } 1}\left(T_{s S c}-T_{\text {wall }}\right) \frac{T_{s S c}}{T_{\text {melt }}} \cdot\left(1-e^{-\frac{m_{s c c}}{m_{E A F}}}\right),
$$

where $K_{\text {waterl }}$ represents the thermal conductance coefficient, which was obtained from approximate heat transfer coefficient of the furnace walls ${ }^{7)}$ taking into account the dimensions of the specific furnace; $T_{s S c}, T_{\text {wall }}$ and $T_{\text {melt }}$ represent the temperatures of the solid steel, the cooling panels and the steel's melting point, respectively; and $\left(1-e^{-\frac{m_{S S C}}{m_{E A F}}}\right)$ represents the exponential decrease of the cooling power with the decreasing mass of solid steel. The expression $\left(1-e^{-\frac{m_{S S C}}{m_{E A F}}}\right)$ might be unusual in the EAF modeling practice; however, as the presented paper studies each EAF zone separately (rather than a whole) the needed cooling powers are directly dependent on the mass of each zone. The expression there- 
fore, accounts for higher or lower cooling power needed for the each zone, when there is more or less material present. A slight non-linear mass dependency could be, without significant loss of accuracy, replaced with completely linear dependence $\left(\frac{m_{S S C}}{m_{E A F}}\right)$; however, exponential behavior has been chosen since the melting of the scrap exhibits minor nonlinear dynamics (due to cone-frustum void, Fig. 3). Similar expressions can also be found in Eqs. (13), (15) and (18), where their interpretation is similar as here.

\section{Liquid metal zone $(l S c)$}

Considering the liquid metal zone, it receives the energy from the arcs $Q_{a r c}$, the oxygen burners $Q_{C H 4}{ }^{\text {(PART 2) }}$, CO post-combustion $Q_{\text {CO-post }}$ (PART $^{2)}$ and chemical reactions $Q_{l S c \text {-chem }}{ }^{\text {(PART 2); }}$ while its energy is lost to the solid steel $Q_{l S c-s S c}$, solid slag $Q_{l S c-s S l}$, liquid slag $Q_{l S c-l S l}$, water-cooled panels $Q_{l s c \text {-water }}$ and gas zone $Q_{l s c \text {-gas. }}$ Like with Eq. (1), $K_{s S c-l s c}$ represents the exposure coefficient between the solid and liquid metal zones. The liquid metal zone also exchanges a significant amount of energy through radiation $Q_{l S c-R A D}$, which is addressed in Section 2.2.1. The energy balance for the liquid metal zone can be represented by Eq. (9):

$$
\begin{aligned}
& Q_{l S c}=\left(Q_{a r c}+Q_{C H_{4}}+K_{p o s t} Q_{C O-p o s t}\right) \cdot K_{s S c-l S c}+Q_{l S c-c h e m} \\
& -Q_{l S c-s S c}-Q_{l S c-s S l}-Q_{l S c-l S l}-Q_{l S c-\text { gas }}-Q_{l S c-\text { water }}-Q_{l S c-R A D} .
\end{aligned}
$$

The arcs' conductive $\left(Q_{\text {arc }}\right)$ and the burners' $\left(Q_{C H 4}\right)$ energy input is obtained with Eqs. (2) and (3), while the CO postcombustion $\left(Q_{\text {CO-post }}\right)$ and chemical energy $\left(Q_{l s c-c h e m}\right)$ equations are addressed in part $2^{\text {(PART 2) }}$. Like with the solid zone, the actual energy from the arc, burners and post-combustion transferred to the liquid metal is proportional to the exposure coefficient $K_{s S c-l s c}$ (Eq. (32)). The energy flow between the solid and liquid metal zones $Q_{l S c-s S c}$ is obtained using Eq. (4), while the energy exchange between the liquid metal, liquid slag and solid slag can be determined with the following Eqs. (10) and (11):

$$
\begin{aligned}
& Q_{l S c-s S l}=m_{l S c-s S l} K_{\text {therm } 5} K_{\text {area } 5}\left(T_{l S c}-T_{s S l}\right), \\
& Q_{l S c-l S l}=m_{l S c-l S l} K_{\text {therm } 6} K_{\text {area } 6}\left(T_{l S c}-T_{l S l}\right),
\end{aligned}
$$

where $m_{l S c-s S l}$ and $m_{l S c-l S l}$ represent the masses of either the liquid metal, solid or liquid slag, depending on which one is smaller; $K_{\text {therm } 5}$ and $K_{\text {therm }}$ represent the heat-transfer coefficients; $K_{\text {area } 5}$ and $K_{\text {area } 6}$ represent the area coefficients between liquid metal and solid slag zones; $T_{l S c}, T_{S S l}$ and $T_{l S l}$ represent the temperatures of the liquid metal, solid and liquid slag zones, respectively.

Like with the solid scrap zone, the energy exchanged between the liquid metal and the surrounding gas $Q_{l S c \text {-gas }}$,

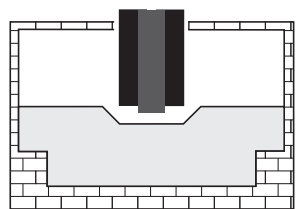

Phase 1

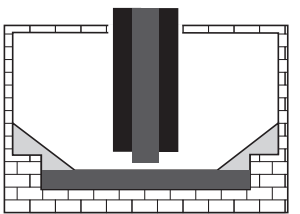

Phase 3

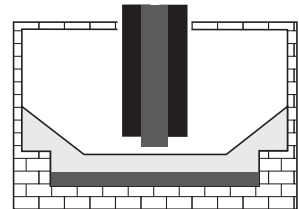

Phase 2

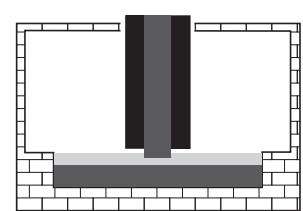

Phase 4
Fig. 3. Four different phases of the scrap-melting process relevant for obtaining the surface areas and view factors. can be described with Eq. (12) as follows:

$$
Q_{l S c-\text { gas }}=\frac{m_{l S c}}{m_{E A F}} K_{\text {therm } 7}\left(T_{l S c}-T_{\text {gas }}\right) \cdot K_{s S c-l S c}, \ldots \ldots
$$

where $m_{l S c}$ represents the current mass of the solid steel; $m_{E A F}$ represents the EAF mass capacity; $K_{\text {therm }} 7$ represents the thermal conductance coefficient; $T_{l S c}$ and $T_{g a s}$ represent the temperatures of the liquid metal and gas zones, respectively; $K_{S S c-l S c}$ represents the exposure coefficient. Coefficient $K_{\text {therm }} 7$ was obtained similarly to coefficient $K_{\text {therm }}$ in Eq. (7) from the approximate heat transfer coefficient for steel ${ }^{7,9,10)}$ and the properties of the specific EAF. Together with fraction $\frac{m_{I S c}}{m_{F}}$ this factor accounts for increasing heat transfer to the gas zone with increasing mass of liquid steel.

Similarly to solid scrap zone, the liquid metal zone also loses energy due to the cooling $\left(Q_{l \text { lsc-water }}\right)$ of the furnace walls, which can be described with Eq. (13):

$$
Q_{l S c-\text { water }}=K_{\text {water } 2}\left(T_{l S c}-T_{\text {wall }}\right) \frac{T_{l S c}}{T_{\text {melt }}} \cdot\left(1-e^{-\frac{m_{I S c}}{m_{E A F}}}\right) \text {, }
$$

where $K_{\text {water } 2}$ represents the thermal conductance coefficient; $T_{l S c}, T_{\text {wall }}$ and $T_{\text {melt }}$ represent the temperatures of the liquid metal, cooling panels and steel melting point, respectively; and $\left(1-e^{-\frac{m_{S C}}{m_{E A F}}}\right)$ represents the exponential increase of the cooling power with the increasing mass of liquid metal, described in Eq. (8).

\section{Solid slag zone $(s S l)$}

The solid slag zone receives the energy from the liquid metal $Q_{l S c-s S l}$, exchanges the energy with the solid steel $Q_{s S c-s S l}$ and loses its energy to the cooling panels $Q_{\text {sSl-water }}$. The energybalance equation is as follows 14:

$$
Q_{s S l}=Q_{s S c-s S l}+Q_{l S c-s S l}-Q_{s S l-w a}
$$

Since the solid slag zone is usually not in direct contact with the liquid slag, gas zone, burners or the arcs, the energy exchange between those zones is ignored. The energy flows $Q_{s S c-s S l}$ and $Q_{l S c-s S l}$ are obtained with Eqs. (5) and (10), respectively. The energy loss due to the cooling $Q_{\text {sSl-water }}$ of the furnace walls can be described with Eq. (15):

$$
Q_{s S l-\text { water }}=K_{\text {water } 3}\left(T_{s S l}-T_{\text {wall }}\right) \frac{T_{s S l}}{T_{\text {melt }}} \cdot\left(1-e^{-\frac{m_{s S l}}{m_{E A F}}}\right),
$$

where $K_{\text {water } 3}$ represents the thermal conductance coefficient; $T_{s S l}, T_{\text {wall }}$ and $T_{\text {melt }}$ represent the temperatures of the solid slag, cooling panels and steel melting point, respectively; and $\left(1-e^{-\frac{m_{S L}}{m_{E A F}}}\right)$ represents the exponential decrease of the cooling power with the decreasing mass of solid slag, described in Eq. (8).

\section{Liquid slag zone $(l S l)$}

The liquid slag zone receives energy from the liquid metal $Q_{I S c-I S l}$; while its energy is lost to solid steel zone $Q_{s S c-l S l}$,

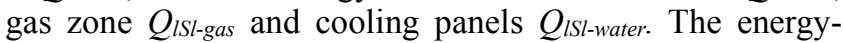
balance equation can be written as follows 16 :

$$
Q_{l S l}=Q_{l S c-l S l}+Q_{s S c-l S l}-Q_{l S l-g a s}-Q_{l S l-w}
$$

The heat exchange between the liquid slag and gas zones $\left(Q_{l S l-\text { gas }}\right)$ can be defined with the following Eq. (17):

$$
Q_{l S l-\text { gas }}=\frac{m_{l S l}}{m_{E A F}} K_{\text {therm } 8}\left(T_{l S l}-T_{\text {gas }}\right) \cdot K_{s S c-l S c},
$$

where $m_{l S l}$ represents the current mass of the liquid slag; $m_{E A F}$ represents the EAF mass capacity; $K_{\text {therm } 8}$ represents the thermal conductance coefficient; $T_{l S l}$ and $T_{\text {gas }}$ represent the temperatures of the liquid slag and gas zones, respectively; $K_{s S c-l S c}$ represents the exposure coefficient. Similarly to coefficients $K_{\text {therm } 4}$ and $K_{\text {therm }} 7, K_{\text {therm } 8}$ is obtained from. ${ }^{7,9,10)}$ Together with fraction $\frac{m_{I S I}}{m_{E A F}}$ the factor accounts 
for increasing heat transfer to the gas zone with increasing mass of liquid slag.

The energy loss due to the cooling $Q_{\text {ISl-water }}$ of the furnace walls can be described with Eq. (18):

$$
Q_{l S l-\text { water }}=K_{\text {water } 4}\left(T_{l S l}-T_{\text {wall }}\right) \frac{T_{l S l}}{T_{\text {melt }}} \cdot\left(1-e^{-\frac{m_{I S l}}{m_{E A F}}}\right),
$$

where $K_{\text {water } 4}$ represents the thermal conductance coefficient; $T_{l S l}, T_{\text {wall }}$ and $T_{\text {melt }}$ represent the temperatures of the liquid slag, cooling panels and steel melting point, respectively; and $\left(1-e^{-\frac{m_{S I}}{m_{E A F}}}\right)$ represents the exponential increase of the cooling power with the increasing mass of liquid slag, described in Eq. (8).

Like as in Eq. (14), the liquid slag is not in direct contact with the solid slag; therefore, the energy exchange between those zones is ignored. Since the electric arcs tend to displace the liquid slag to reach the liquid metal zone, the energy received from the arcs is neglected. One would expect that the energy-balance equation for the liquid slag zone would also include the radiative heat exchange. Even though this would be sound from the physical point of view, it is very difficult to determine the radiative relations between the liquid slag and the other surfaces, mostly in the conditions before the flat-bath period. For this reason we decided not to consider the radiative heat transfer in the case of the liquid slag zone. Consequently, the parameters regarding the liquid slag zone had to be adjusted accordingly. On the other hand, the liquid slag zone has a direct impact on the radiative heat transfer of the liquid metal zone, which is discussed later.

\section{Gas zone ( $g a s)$}

The gas zone receives energy from the arcs $Q_{\text {arc-gas, }}$, the oxygen burners $Q_{\mathrm{CH} 4 \text {-gas }}{ }^{\text {(PART 2) }}$ and the CO post-combustion $Q_{\text {CO-post }}{ }^{\text {(ART 2) }}{ }^{\text {, depending on the post-combustion inefficien- }}$ cy $\left(1-K_{\text {post }}\right)$, exchanges the energy with solid steel $Q_{s S c \text {-gas }}$, liquid metal $Q_{l s c \text {-gas }}$ and liquid slag $Q_{l s l \text {-gas; }}$; while its energy is lost to the cooling panels $Q_{\text {gas-water }}$. The energy-balance equation is as follows 19 :

$$
\begin{aligned}
& Q_{\text {gas }}=Q_{\text {arc-gas }}+\left(1-K_{\text {post }}\right) Q_{C O-p o s t}+Q_{C H 4-\text { gas }} \\
& +Q_{s S c-\text { gas }}+Q_{l S c-\text { gas }}+Q_{l S l-\text { gas }}-Q_{\text {gas-water }} .
\end{aligned}
$$

The coefficient of post-combustion efficiency $\left(K_{\text {post }}\right)$ in Eq. (19) shows that the energy of the CO post-combustion, which is not consumed by either solid or liquid metal, is transferred to the gas zone and mostly represents a loss of useful energy.

The gas-zone interactions with the solid steel $Q_{s S c \text {-gas }}$, liquid metal $Q_{l s c \text {-gas }}$ and liquid slag $Q_{l S l \text {-gas }}$ zones have already been presented with Eqs. (7), (12) and (17). The energy dissipated from the arcs and burners also heats the gas zone, which is obtained by Eqs. (20) and (21):

$$
\begin{aligned}
& Q_{\text {arc-gas }}=0.025 \cdot P_{\text {arc }} \text {, } \\
& Q_{\mathrm{CH}_{4} \text {-gas }}=\Delta H_{T-n}^{\circ}\left(1-K_{\text {burn }} \cdot\left(0.35+0.65 \tanh \left(\frac{1300^{\circ} \mathrm{C}}{T_{s S c}}-1\right)\right)\right) \text {, }
\end{aligned}
$$

where $P_{\text {arc }}$ represents the total arc powers and 0.025 represents the approximated fraction of the arcs' energy heating the gas zone; $\Delta H_{T-n}^{\circ}{ }^{\text {(PART 2) }}$ represents the burner power and $\left(1-K_{\text {burn }} \cdot\left(0.35+0.65 \tanh \left(\frac{1300^{\circ} \mathrm{C}}{T_{\text {sc }}}-1\right)\right)\right.$ describes the hyperbolic tangent approximation of the relation between the solid scrap temperature and the burner efficiency (similar to Eq. (3)). Meaning that the decreased burner efficiency due to higher scrap temperature heats the gas zone instead of the steel. Due to the small masses of the solid slag, which is usually placed on the bottom of the furnace, the solid slag zone has no energy relation to the gas zone. The energy loss due to the cooling $Q_{\text {gas-water }}$ of the furnace roof and walls, can be described by Eq. (22):

$Q_{\text {gas-water }}=K_{\text {water } 5}\left(\left(T_{\text {gas }}-T_{\text {roof }}\right) \frac{A_{1}}{A_{1}+A_{2}}+\left(T_{\text {gas }}-T_{\text {wall }}\right) \frac{A_{2}}{A_{1}+A_{2}}\right)$,

where $K_{\text {water } 5}$ represents the thermal conductance coefficient; $T_{\text {gas }}, T_{\text {roof }}$ and $T_{\text {wall }}$ represent the temperatures of the gas and the roof- and wall-cooling panels, respectively.

Fractions $\frac{A_{1}}{A_{1}+A_{2}}$ and $\frac{A_{2}}{A_{1}+A_{2}}$ define the portion of the gas energy transferred either to roof or wall zone, depending on their surface areas $A_{1}$ and $A_{2}$.

\subsubsection{Radiative Heat Transfer}

The radiative heat transfer represents a significant amount of the total heat transferred in the EAF. For the purpose of this study the furnace is considered as an enclosure with $N$ surfaces, all treated as gray bodies. The gray-body radiosity $J_{i}$ can be determined with Eq. (23): ${ }^{11)}$

$$
J_{i}=\varepsilon_{i} \sigma_{S B} T_{i}^{4}+\left(1-\varepsilon_{i}\right) \sum_{j=1}^{N}\left(V F_{i j} \cdot J_{j}\right),
$$

where $\varepsilon_{i}$ represents the body's emissivity [0-1], $\sigma_{S B}$ represents the Stefan-Boltzmann constant, $T_{i}$ represents the body's temperature, $V F_{i j}$ represents the view-factor from surface $i$ to surface $j[0-1]$ and $J_{j}$ represents the radiosity of the body $j$. The first part of Eq. (23) represents the graybody radiation according to the Stefan-Boltzmann law, while the second part of the equation represents the incident radiation, which is the sum of the radiations from all the other surfaces per unit of surface area $i$.

Obtaining the radiosity for all the bodies in the furnace, radiative heat transfer $Q_{i-R A D}$ for the surface $i$ can be computed with Eq. (24): ${ }^{11)}$

$$
Q_{i-R A D}=A_{i} \sum_{j=1}^{N} V F_{i j}\left(J_{i}-J_{j}\right),
$$

where $A_{i}$ represents the surface $i$ area, $V F_{i j}$ represents the view factor from surface $i$ to surface $j$ and $J_{i}$ and $J_{j}$ represent the radiosities of surfaces $i$ and $j$, respectively.

For greater transparency of the following equations, a similar notation to MacRosty ${ }^{3)}$ was used, numbering the surfaces relevant for the radiative heat transfer as follows: 1roof, 2-walls, 3-solid scrap, 4-liquid metal and 5-arcs. The arcs are considered to be a black bodies and transparent when receiving the radiative energy.

According to the above equations, radiosities for all the surfaces can be obtained with Eq. (25), with the following simplifications regarding the incident radiation: the roof and walls receive the radiative heat from all the other surfaces; the solid steel and liquid metal do not exchange heat by means of the radiation, since they are in direct contact and conductive heat transfer prevails.

$$
\begin{aligned}
& J_{\text {roof }}=J_{1}=\varepsilon_{1} \sigma_{S B} T_{1}^{4}+\left(1-\varepsilon_{1}\right)\left(V F_{1-2} J_{2}+V F_{1-3} J_{3}+V F_{1-4} J_{4}+V F_{1-5} J_{5}\right), \\
& J_{\text {wall }}=J_{2}=\varepsilon_{2} \sigma_{S B} T_{2}^{4}+\left(1-\varepsilon_{2}\right)\left(V F_{2-1} J_{1}+V F_{2-3} J_{3}+V F_{2-4} J_{4}+V F_{2-5} J_{5}\right), \\
& J_{s S c}=J_{3}=\varepsilon_{3} \sigma_{S B} T_{3}^{4}+\left(1-\varepsilon_{3}\right)\left(V F_{3-1} J_{1}+V F_{3-2} J_{2}+V F_{3-5} J_{5}\right), \\
& J_{l S c}=J_{4}=\varepsilon_{4} \sigma_{S B} T_{4}^{4}+\left(1-\varepsilon_{4}\right)\left(V F_{4-1} J_{1}+V F_{4-2} J_{2}+V F_{4-5} J_{5}\right),
\end{aligned}
$$

where $\varepsilon$ are the emissivities of the surfaces.

At this point the radiative power of the arc is also needed, which is determined with Eq. (26). Since the conductive heat transfer from the arcs is defined as 0.20 of the total arc 
power, the radiative heat transfer, considering the losses and energy transferred to the gas (0.05), is defined as 0.75 of the total arc power:

$$
Q_{\text {arc }-R A D}=0.75 \cdot P_{a r c},
$$

Later, radiative heat flows can be obtained for all the surfaces using Eq. (27):

$$
\begin{aligned}
Q_{\text {roof }-R A D} & =A_{1} \cdot\left(V F_{1-2}\left(J_{1}-J_{2}\right)+V F_{1-3}\left(J_{1}-J_{3}\right)+V F_{1-4}\left(J_{1}-J_{4}\right)\right)- \\
& V F_{5-1} Q_{\text {arc }-R A D}, \\
Q_{\text {wall }-R A D} & =A_{2} \cdot\left(V F_{2-1}\left(J_{2}-J_{1}\right)+V F_{2-3}\left(J_{2}-J_{3}\right)+V F_{2-4}\left(J_{2}-J_{4}\right)\right)- \\
& V F_{5-2} Q_{\text {arc }-R A D}, \\
Q_{s S c-R A D} & =A_{3} \cdot\left(V F_{3-1}\left(J_{3}-J_{1}\right)+V F_{3-2}\left(J_{3}-J_{2}\right)\right)-V F_{5-3} Q_{a r c-R A D}, \\
Q_{I S c-R A D} & =A_{4} \cdot\left(V F_{4-1}\left(J_{4}-J_{1}\right)+V F_{4-2}\left(J_{4}-J_{2}\right)\right)-V F_{5-4} Q_{a r c-R A D}
\end{aligned}
$$

The negative value of the $Q_{i-R A D}$ indicates that the surface $i$ receives the radiative energy from other surfaces, since $Q_{i \text { - }}$ $R A D$ denotes the energy flow leaving the surface $i$.

View factors and surface areas

As can be seen in Eqs. (25) and (27) the amount of radiative heat transfer between the surfaces is dependent on the surface emissivities, temperatures, surface areas and view factors from one surface to another. At this point the relations between the view factors, the surface areas and the geometry of the furnace and the steel are considered.

As assumed, the EAF can be represented as an enclosure with $N$ surfaces, meaning that the sum of all the view factors from one surface to the others is 1, as given by Eq. (28):

$$
\sum_{j=i}^{N} V F_{i-j}=1 .
$$

By definition, a view-factor reciprocity rule applies between two surfaces, as follows $29:^{11)}$

$$
A_{i} \cdot V F_{i-j}=A_{j} \cdot V F_{j-i}
$$

meaning that a view factor from surface $i$ to $j$ equals the view factor from surface $j$ to $i$ multiplied by the ratio of surface areas $\frac{A_{j}}{A}$. The definitions 28 and 29 are useful when determining the view factors between complex surfaces, as they can be obtained from other view factors in an enclosure.

All the surfaces in the furnace are considered as simple geometric shapes with different orientations, such as discs, rings, cylinders, cone-frustums or different combinations of these. During the melting process the geometric ratios between the surfaces change as a consequence of scrap melting and new scrap loading. Typical phases of the melting progress can be represented by Fig. 3, which shows that there are four phases of the scrap-melting process relevant for determining the surface areas and view factors. After the initial charge of the furnace, the electrodes bore themselves into the scrap, creating a cone-frustum shaped void. As the melting progresses, the radius of the frustum increases and eventually reaches the edge of the furnace (phase 1). Afterwards, the frustum-shaped void starts to move downwards, exposing more and more of the wall's surface (phase 2). When a sufficient amount of scrap melts, the level of the liquid metal is reached by the arcs (phase 3 ). From this point on, the energy flow into the liquid metal increases, while the flow into the solid scrap decreases rapidly. When the melting process approaches an end, all of the scrap is molten and slag starts to foam (phase 4). Also visible in Fig. 3 is the fact that the initial (solid) and final (liquid) volumes of the metal are not the same, which is due to the bulk densities of the solid $\left(\rho_{\mathrm{sSc}}=900 \frac{\mathrm{kg}}{\mathrm{m}^{3}}\right)$ and liquid $\left(\rho_{\mathrm{ISc}}=7000 \frac{\mathrm{kg}}{\mathrm{m}^{3}}\right)$ metals. $\left.^{12}\right)$

To determine the surface areas and view factors, the following EAF geometry and associated annotation was used as shown in Fig. 4.

The dimensions of the exposed walls $\left(h_{\text {wall }}\right)$, scrap height $\left(h_{\text {scrap } 1}, h_{\text {scrap } 2}\right)$, bath height $\left(h_{\text {bath }}\right)$, slag height $\left(h_{\text {slag }}\right)$ and cone frustum ( $\left.h_{\text {cone }}, r_{\text {cone in }}, r_{\text {cone out }}\right)$ are obtained from the scrap and slag melting Eqs. (42), (43), (46) and (47) discussed later. The arc length $\left(h_{\text {arc }}\right)$ is obtained from the EAF electric model proposed in our previous paper. ${ }^{1)}$ The other non-variable dimensions are: $r_{\text {eaf out }}=6.6 \mathrm{~m}, r_{\text {eaf in }}=4.9 \mathrm{~m}$, $r_{\text {hole }}=3.4 \mathrm{~m}, h_{\text {eaf up }}=2.9 \mathrm{~m}$ and $h_{\text {eaf low }}=1.0 \mathrm{~m}$.

The view factors needed in the radiative heat-transfer Eq. (27) are obtained from different sources that have studied radiative heat transfer, ${ }^{11,13,14)}$ assuming the inner zones of the EAF to be as follows: roof $=$ ring (outer diameter $-r_{\text {eaf out }}$, inner diameter $\left.-r_{\text {hole }}\right)$, walls $=$ cylinder $\left(\right.$ height $-h_{\text {wall }}$, diameter $\left.-r_{\text {eaf out }}\right)$, steel scrap $=$ cone frustum attached to coaxial ring (cone height $-h_{\text {cone }}$, cone outer diameter - $r_{\text {cone out }}$, cone inner diameter $-r_{\text {cone in }}$, ring diameters $-r_{\text {eaf out }}$ and $\left.r_{\text {cone out }}\right)$, liquid metal $=$ disc $\left(\right.$ diameter $r_{\text {eaf }}$ in $)$. The arcs are assumed to be cylindrical, although in reality the arcs tend to extend at the bottom, forming a parabolic shape, which behaves chaotically. ${ }^{15)}$

Since the energy dissipated from the electric arcs prevails in a radiative form, the view factors from the arcs to other surfaces in the furnace play a significant role. When dealing with a flat-bath situation in an EAF, the view factors from the arcs could be obtained relatively easily. However, when considering the situation prior to the flat bath, i.e., solid scrap is present, the view factors from the arc tend to change as the scrap melts and are more difficult to determine. Considering the paper published by MacRosty, ${ }^{3)}$ the arc-tosolid-scrap view factor $\left(V F_{5-3}\right)$ is approximated as an exponential function $0.9-e^{r_{b}} / 42$, where $r_{b}$ is a cone-frustum base radius. It is generally known that the electrodes bore into the solid scrap at the beginning of each basket, meaning that the view factor from the arc to the scrap increases rapidly as the electrode progresses its way into the scrap and then gradually decreases when the scrap surrounding the electrode melts. In this manner we propose the view factor from the arc to the solid $\left(V F_{5-3}\right)$ or liquid $\left(V F_{5-4}\right)$ scrap, considering the view factor reciprocity rule, to be determined as follows with Eqs. (30) and (31):

$$
\begin{gathered}
V F_{5-3}=\left(1-V F_{5-1}-V F_{5-2}\right) K_{s S c-l S c}, \ldots \\
V F_{5-4}=\left(1-V F_{5-1}-V F_{5-2}\right)\left(1-K_{s S c-l s c}\right),
\end{gathered}
$$

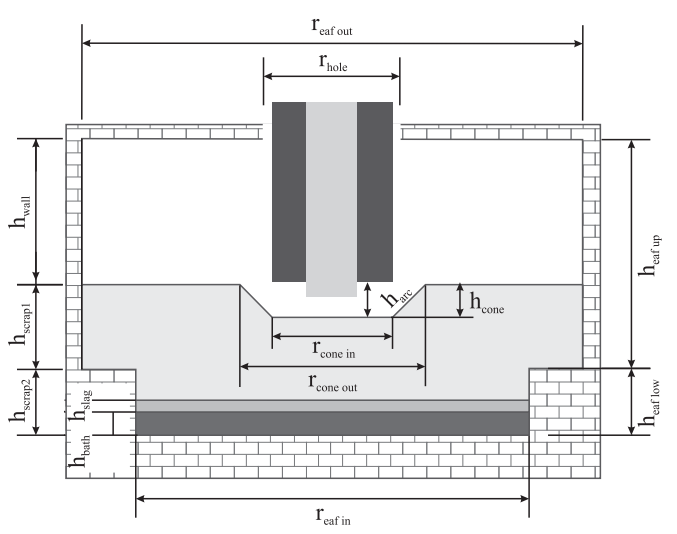

Fig. 4. EAF geometry used for computing the surface areas and view factors. 
where $K_{S S c-l S c}$ is the exposure coefficient [0-1], which determines the exposure of the solid or liquid metal and is approximated with a tangent-hyperbolic function from the amount of solid and liquid metal (height), as shown in Eq. (32):

$$
K_{s S c-l S c}=0.5 \cdot \tanh \left(5\left(h_{b a t h}-h_{\text {scrap } 1}-h_{\text {scrap } 2}+h_{\text {cone }}\right)\right)+0.5,
$$

where $h_{\text {bath }}, h_{\text {scrap } 1}, h_{\text {scrap } 2}$ and $h_{\text {cone }}$ define the solid and liquid metal height and the depth of the electrodes in the cone frustum, respectively, and are shown in Fig. 4. Briefly, the tangent-hyperbolic relation between the steel heights determines which zone (solid or liquid) is more exposed and rather than being "on-off" assures continuous dynamics when the scrap cone void drops to reach the bath height. The view factors $V F_{5-1}$ and $V F_{5-2}$ needed in Eqs. (30) and (31) are obtained as a cylinder to coaxial ring (arcs to roof) and a cylinder inside or outside the radial cylinder (arcs to walls). The view factors $V F_{5-1}$ and $V F_{5-2}$ are reduced by the (1- $\left.K_{\text {slag }}\right)$ factor, where $K_{\text {slag }}$ denotes the slag impact on the arc's radiative heat to the roof and walls and is presented in detail in part $2^{\text {(PART 2) }}$. Some additional factors to further increase or decrease the factors depending on the solid scrap distribution, which exceeds the scope of this paper, will be addressed in another paper.

\subsection{Rate of Temperature Change}

As a consequence of the heat-balance equations, the temperature of each EAF zone changes according to the firstorder differential Eqs. (33) to (37). A methodology similar to Bekker ${ }^{2}$ and MacRosty ${ }^{3)}$ was employed (and extended to slag zones), since the relation between the energy and the temperature is derived from the fundamental laws (see assumption):

$$
\begin{gathered}
\frac{d T_{s S c}}{d t}=\frac{Q_{s S c}\left(1-\frac{T_{s s c}}{T_{\text {melt }}}\right)}{m_{s S c} C_{p, s S c}}, \\
\frac{d T_{l S c}}{d t}=\frac{Q_{l S c}}{m_{l S c} C_{p, l S c}}, \ldots \\
\frac{d T_{s S l}}{d t}=\frac{Q_{s S l}\left(1-\frac{T_{s S l}}{T_{\text {melt }}}\right)}{m_{s S l} C_{p, s S l}}, \\
\frac{d T_{l S l}}{d t}=\frac{Q_{l S l}}{m_{l S l} C_{p, l S l}}, \ldots \\
\frac{d T_{\text {gas }}}{d t}=\frac{Q_{\text {gas }}}{m_{g a s} C_{p, g a s}}, \ldots
\end{gathered}
$$

where $Q_{x x}$ denotes the energy provided to each of the zones, $T_{x x}$ represents the temperatures of the zones, $m_{x x}$ represents the current masses of each zone and $C_{p, x x}$ represents the specific heat capacity for each zone. Suffix $x x$ denotes the appurtenant zone. The factors $\left(1-\frac{T_{s S c}}{T_{\text {melt }}}\right)$ and $\left(1-\frac{T_{s S l}}{T_{\text {melt }}}\right)$ represent the energy that is heating the zone and assures that its temperature cannot rise above the melting point.

Since each EAF zone is homogenous in all aspects (see assumptions), whether the change of mass should appear due to the addition of the material (charging a new basket, slag addition, etc.), the temperature of the zone is re-determined using Eq. (38):

$$
T_{x x}=\frac{T_{x x} m_{x x}+T_{\text {addition }} m_{\text {addition }}}{m_{x x}+m_{\text {addition }}},
$$

where ${ }_{x x}$ represents the particular EAF zone and addition represents the material added to the zone. Since each zone pos- sesses equal characteristics (see assumption), $C_{p, x x}$ can be excluded from the equation.

As was mentioned previously, besides the standard EAF zones, two more zones are used for determining the heat losses due to the cooling of the furnace, i.e., the roof and the wall zones. The temperatures of the roof and walls can be determined with Eqs. (39) and (40):

$$
\begin{gathered}
\frac{d T_{\text {roof }}}{d t}=\frac{-Q_{1-R A D}+\frac{A_{1}}{A_{1}+A_{2}} Q_{\text {gas-water }}-\phi_{1-H_{2} O} C_{p, H_{2} O}\left(T_{\text {roof }}-T_{H_{2} O-\text { in }}\right)}{A_{1} d_{1} \rho_{1} C_{p, \text { roof }}}, \\
\frac{d T_{\text {wall }}}{d t}=\frac{-Q_{2-R A D}+\frac{A_{2}}{A_{1}+A_{2}} Q_{\text {gas-water }}-\phi_{2-H_{2} O} C_{p, H_{2} O}\left(T_{\text {wall }}-T_{H_{2} O-\text { in }}\right)}{A_{2} d_{2} \rho_{2} C_{p, \text { wall }}},
\end{gathered}
$$

where $\boldsymbol{\Phi}_{1-\mathrm{H}_{2} \mathrm{O}}$ and $\boldsymbol{\Phi}_{2-\mathrm{H} 2 \mathrm{O}}$ represent the water flow rates (constant, approx. $\Phi_{1-H 2 O}=60 \mathrm{~kg} / \mathrm{s}$ and $\left.\Phi_{2-H 2 O}=130 \mathrm{~kg} / \mathrm{s}\right)$, $C_{p, H 2 O}$ represents the water specific heat capacity, $T_{H 2 O-i n}$ represents the ingoing water temperature, $A_{1}$ and $A_{2}$ represent the surface areas of the roof and the walls, $d_{l}$ and $d_{2}$ represent the thickness of the roof and the walls, $\rho_{1}$ and $\rho_{2}$ represent the material density of the roof and the walls, $C_{p, \text { roof }}$ and $C_{p, \text { wall }}$ represent the specific heat capacity of the roof and walls, fractions $\mathrm{A} 1 /(\mathrm{A} 1+\mathrm{A} 2)$ and $\mathrm{A} 2 /(\mathrm{A} 1+\mathrm{A} 2)$ define the portion of the gas energy transferred to roof and wall zones, respectively. Other cooling losses (furnace hearth) can be defined by Eq. (41):

$$
Q_{\text {water }}=Q_{s S c \text {-water }}+Q_{l S c \text {-water }}+Q_{s S l-w a t e r}+Q_{l S l-w}
$$

At this point the model assumes invariable water flows $\boldsymbol{\Phi}_{1-H 2 O}$ and $\Phi_{2-H 2 O}$ across the panels without the pressure drop; as for the real processes the flows are slightly variable. ${ }^{16,17)}$ Determining the temperatures of the roof and walls is important when the EAF model is used for optimization purposes. When applying the optimization, it could be possible that the routine parameterizes the model in a way that would increase the power of the arcs in order to reach the energy optimum; however, the temperatures of the cooling panels should be taken into account, since the high radiative impact of the arcs damages the furnace linings.

\subsection{Mass Transfer Model}

With the heat-balance and temperature-gradient equations determined, the mass-balance models for each of the EAF zones can be defined. The melt rate of the solid scrap can be defined using the following Eqs. (42) and (43):

$$
\begin{gathered}
\dot{m}_{s S c}=-\frac{Q_{s S c} \frac{T_{s s c}}{T_{\text {melt }}}}{\lambda_{s S c}+C_{p, s S c}\left(T_{m e l t}-T_{s S c}\right)}, \\
\dot{m}_{l S c}=-\dot{m}_{s S c}, \ldots \ldots \ldots \ldots \ldots \ldots
\end{gathered}
$$

where $m_{s S c}$ and $m_{l S c}$ are the masses of the solid and liquid metal and $\lambda_{s S c}$ is the latent heat of fusion of the scrap. The factor $\frac{T_{S S c}}{T_{\text {melt }}}$ represents the fraction of energy that is melting the solid scrap. Other variables appearing in the equations were already addressed. Since the mass of Fe is much larger than the other dissolved elements $(\mathrm{C}, \mathrm{Si}, \mathrm{Mn}, \mathrm{Cr}$ and $\mathrm{P})$, the latent heat of fusion and the specific heat capacity is assumed to be equal to those of Fe.

At any point, the overall mass of liquid Fe can be obtained from Eq. (43) subtracting all the masses of other dissolved elements and adding $m_{F e}$ from Eq. (30) in the part $2^{\text {(PART 2) }}$, which yields Eq. (44):

$$
m_{F e-t o t a l}=m_{l S c}-\sum_{i} m_{i}+m_{F e}, i=C, S i, M n, C r, P
$$


Equation (44) unlike Eq. (43) also includes mass changes due to the progress of the chemical reactions. The total mass of the liquid metal zone can be obtained by adding the actual masses of the dissolved elements to the mass of the liquid Fe defined in part $2^{\text {(PART 2) }}$, which gives Eq. (45):

$$
m_{l S c-\text { total }}=m_{\mathrm{Fe}-\text { total }}+\sum_{i} m_{i}, i=C, \mathrm{Si}, \mathrm{Mn}, \mathrm{Cr}, \mathrm{P}
$$

where $m_{i}$ denotes the actual mass of the element in the bath.

Similarly, the melt rate of the solid slag can be defined using Eqs. (46) and (47):

$$
\begin{gathered}
\dot{m}_{l S l}=\frac{Q_{s S l} \frac{T_{s s l}}{T_{m e l t}}}{\lambda_{s S l}+C_{p, s S l}\left(T_{m e l t}-T_{s S l}\right)}, \\
\dot{m}_{s S l}=-\dot{m}_{l S l}, \ldots \ldots \ldots \ldots \ldots
\end{gathered}
$$

where $m_{s S l}$ and $m_{l S l}$ are the masses of solid and liquid slag and $\lambda_{s S l}$ is the latent heat of fusion of the slag. The factor $\frac{T_{s S l}}{T_{\text {melt }}}$ represents the energy that is melting the solid scrap. The other variables appearing in the equations were already addressed.

Like with the temperature-change equations, the mass of each zone should be re-determined when different additions are added to the zones 48 :

$$
m_{x x}=m_{x x}+m_{\text {addition }} .
$$

\section{Results and Discussion}

The following section presents the simulation results obtained from the developed mathematical models for the mass and heat transfer and the chemical reactions from both parts of the paper; however, only the results relevant to this paper are presented in the following. Some of the obtained results are compared with the available endpoint measurements. Since the EAF idle data (basket loading, electrode maintenance, etc.) does not represent any significant information about the melting process (except the tap-to-tap times, which are thus far not relevant for this study), it has been removed from the measurements and is therefore not used as a part of the model's validation.

\subsection{Simulation Timeline}

Figure 5 and Table 1 show the timeline of the simulation, relevant for obtaining the simulation results presented here and in part 2. The actions presented in the timeline are defined according to the actual EAF melting process obtained from the operational data. All the units except $Q_{a r c}$ (MW), Charge (ton) and Time (s) are in kg/s.

Observing Fig. 5 and Table 1, Charge represents the scrap loading in tons (loaded at times $0 \mathrm{~s}, 900 \mathrm{~s}$ and $1500 \mathrm{~s}$ ), Q Q arc represents the sum of the arc powers in $\mathrm{MW}, \mathrm{O}_{2}$ rate represents the oxygen lancing rate, $\mathrm{O}_{2}$ post represents the oxygen lancing rate for $\mathrm{CO}$ post-combustion, $C$ rate represents the carbon injection rate, offgas represents the offgas flow rate, $\mathrm{CH}_{4}$ rate represents the oxygen burners injection rate and Slag represents the rate of addition of slag-forming materials.

\subsection{Mass Transfer Model}

Figure 6 shows the results of the mass-transfer model for each of the EAF zones.

As can be seen, at times $900 \mathrm{~s}$ and $1500 \mathrm{~s}$ when a new basket of scrap is loaded, the mass of solid steel increases instantly. Shortly after each charge a rapid increase in liquid steel can be observed, which is a consequence of high exposure of the solid steel to the arcs. When a significant amount of solid steel melts more energy is transferred to liquid steel

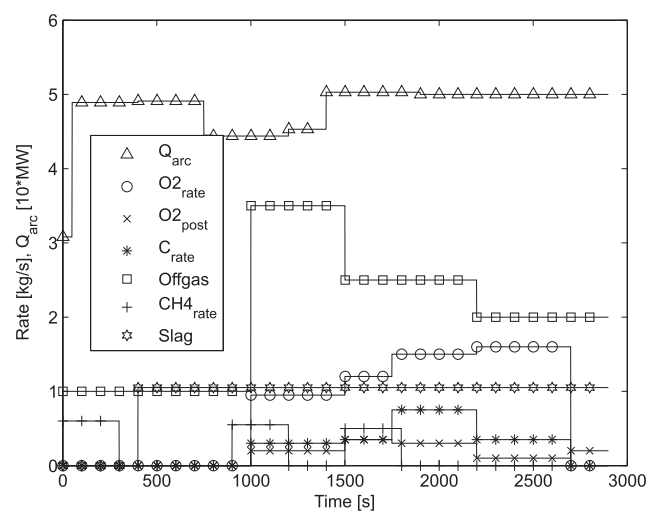

Fig. 5. Simulation timeline.

Table 1. Timeline of the simulation.

\begin{tabular}{rrrrrrrrr}
\hline $\begin{array}{c}\text { Time } \\
\text { [s] }\end{array}$ & $\begin{array}{c}\text { Charge } \\
\text { [ton] }\end{array}$ & $\begin{array}{c}Q_{\text {arc }} \\
{[\mathrm{MW}]}\end{array}$ & $O_{2}$ rate & $O_{2}$ post & Crate & offgas & CH $H_{4}$ rate & Slag \\
\hline 1 & 40 & 48.9 & 0.00 & 0.00 & 0.00 & 10 & 0.60 & 0.00 \\
300 & 0 & 48.9 & 0.00 & 0.00 & 0.00 & 10 & 0.00 & 0.00 \\
400 & 0 & 49.1 & 0.00 & 0.00 & 0.00 & 10 & 0.00 & 1.05 \\
800 & 0 & 44.4 & 0.00 & 0.00 & 0.00 & 10 & 0.00 & 1.05 \\
900 & 25 & 44.4 & 0.00 & 0.00 & 0.00 & 10 & 0.55 & 1.05 \\
1000 & 0 & 44.4 & 0.95 & 0.20 & 0.30 & 30 & 0.55 & 1.05 \\
1200 & 0 & 45.3 & 0.95 & 0.20 & 0.30 & 30 & 0.00 & 1.05 \\
1400 & 0 & 50.3 & 0.95 & 0.20 & 0.30 & 30 & 0.00 & 1.05 \\
1500 & 20 & 50.3 & 1.20 & 0.35 & 0.35 & 25 & 0.55 & 1.05 \\
1750 & 0 & 50.3 & 1.50 & 0.30 & 0.75 & 25 & 0.00 & 1.05 \\
1900 & 0 & 50.0 & 1.50 & 0.30 & 0.75 & 20 & 0.00 & 1.05 \\
2200 & 0 & 50.0 & 1.60 & 0.10 & 0.35 & 20 & 0.00 & 1.05 \\
\hline
\end{tabular}

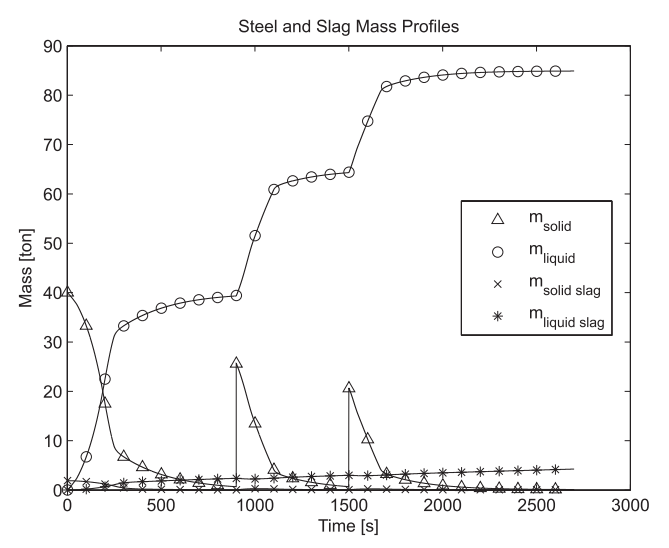

Fig. 6. Rate of change of masses in different EAF zones.

and the melting rate decreases accordingly. Also visible, the mass of the solid slag drops rapidly after the furnace is turned on and remains close to 0 even though slag-forming materials are charged into the furnace, which is a consequence of the fast melting of those materials due to the low rate of their addition compared to the overall mass in the EAF.

\subsection{Temperature Change Model}

Figure 7 shows the temperature changes in the observed EAF zones. Similarly, as in Fig. 6, a decrease in the temperature can be observed at times $900 \mathrm{~s}$ and $1500 \mathrm{~s}$ when a new basket of scrap is loaded. The drop in temperature in the liquid metal zone is higher after the first charge, which affects the solidifying of the liquid metal observable in Fig. 6. As 


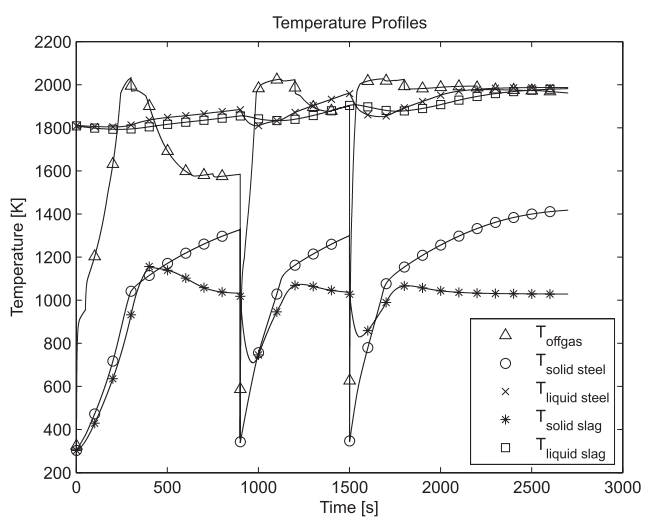

Fig. 7. Rate of change of temperatures in different EAF zones.

proposed by Ref. 18), the temperature of the gas is usually higher than the other zones, which also coincides with the results of our model. The initial gas-zone temperature is 298 $\mathrm{K}$, but this rapidly increases to around $1000 \mathrm{~K}$, which is a consequence of the low heat capacity of the gases and the high temperatures of the oxygen burners and electric arcs. After each charge, the model assumes that the temperature in the gas zone drops to that of the surroundings (298 K) and all the other gases, except $N_{2}$ and $O_{2}$, are released from the EAF freeboard.

As can be seen in Fig. 7, liquid steel temperature already appears at time 0 , even though no liquid steel is present yet. This might seem strange; however, simulation procedure assumes a small initial amount of liquid steel $(1 \mathrm{~kg})$, with the temperature $1809 \mathrm{~K}$ in order to prevent numerical difficulties and simulation instability. Similarly, temperatures of solid steel and slag remain, even though both have already melted, which is also due to the simulation assumption that the final mass of solid steel or slag cannot drop bellow $1 \mathrm{~kg}$. However, when solid steel and slag masses reach their minimum value, they are excluded from further calculations.

\subsection{Heat Transfer Model}

Figure 8 shows the radiative heat transfer between the considered EAF surfaces. As can be observed, the radiative power of the arcs $\left(P_{\text {arc-RAD }}\right)$ reaches up to $33 \mathrm{MW}$, which amounts to approximately $75 \%$ of the active arc powers. The negative characteristic of the curves denotes that the associated surface is receiving the radiative heat, while the positive characteristic denotes a loss of radiative power from that surface. Observing Figs. 8 and 6 simultaneously, we can see the relation between the radiative powers transmitted to either of the zones to its mass. After $t=1700 \mathrm{~s}$ a sharp increase in the radiative power to the liquid zone occurs, which is a consequence of the slag forming, described in Eq. (59) $)^{\text {(PART 2). }}$.

Figure 9 shows the power impacts between the EAF zones and between the arcs and the liquid and solid metal zones. Like with Fig. 8, a relation between the solid and liquid metal masses and the corresponding powers is observable.

As can be seen in Fig. 9 the energy flows between the arcs, the solid and the liquid steel prevail over the energy flows between the steel and the slag zones, which is a consequence of the larger masses of the steel zones compared to the slag zones. Nonetheless, modeling the slag zones separately from the steel zones is important, as each zone possesses its own physical characteristics, which leads to different mass, heat and temperature profiles.

Figure 10 shows the total input energy (power) flows into each zone.

A sharp increase of power to the solid steel zone can be

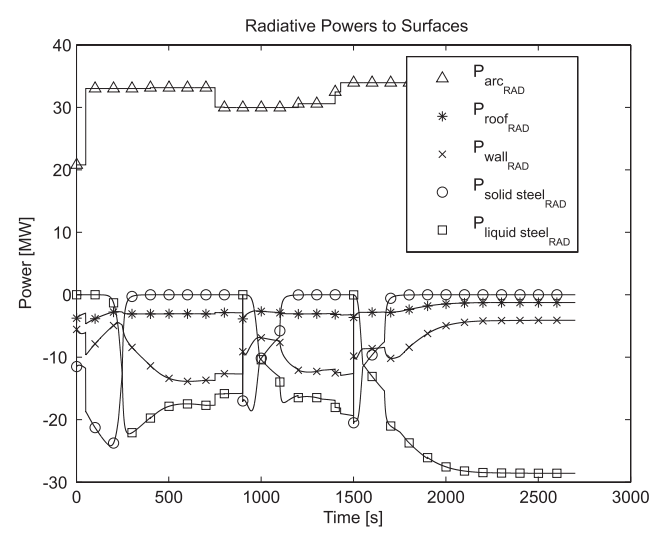

Fig. 8. Radiative heats between EAF surfaces.

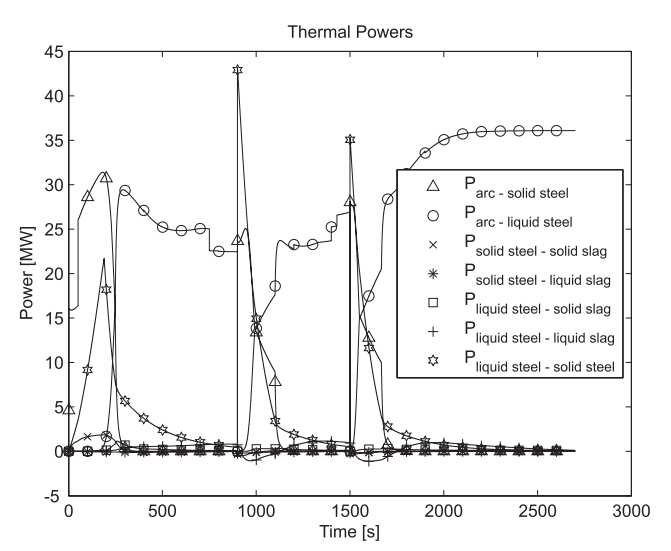

Fig. 9. Energy exchange between EAF zones.

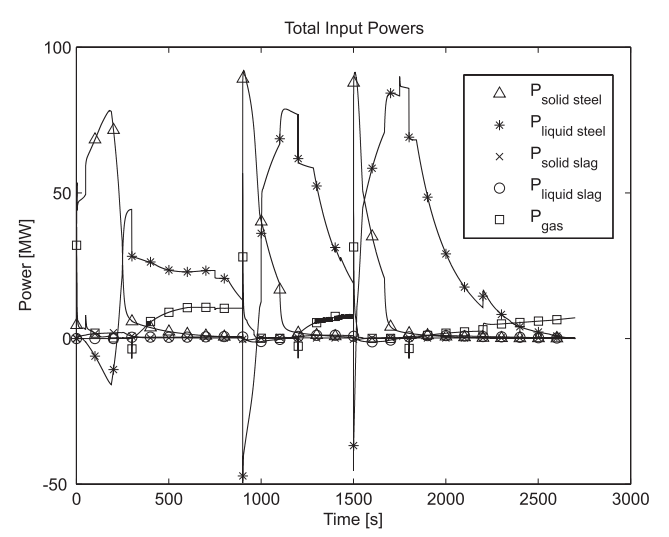

Fig. 10. Total energy input to each EAF zone.

observed after each charge, which is mostly a consequence of the increased energy transfer from the liquid and gas zones to the solid scrap. Like with Fig. 9, lower powers to the slag zones are observable, where the reasons for that were already mentioned.

Figure 11 shows the temperatures of the cooling panels and the total loss of energy (power) for each zone due to the cooling of the furnace vessel or due to the gases extracted to offgas.

It can be seen that a relatively constant power (energy) is lost due to the extraction of gases. Shortly after the first and second charge, greater loss of energy and increased wall temperature $\left(T_{\text {wall }}\right)$ occur to the liquid zone, as a consequence of the flat-bath conditions to prevent the furnace from overheating. Also visible at times $900 \mathrm{~s}$ and $1500 \mathrm{~s}$ is a sharp increase in the gas cooling power $\left(P_{\text {water-gas }}\right)$ and the roof-cooling temperature $\left(T_{\text {roof }}\right)$, which occur due to higher 

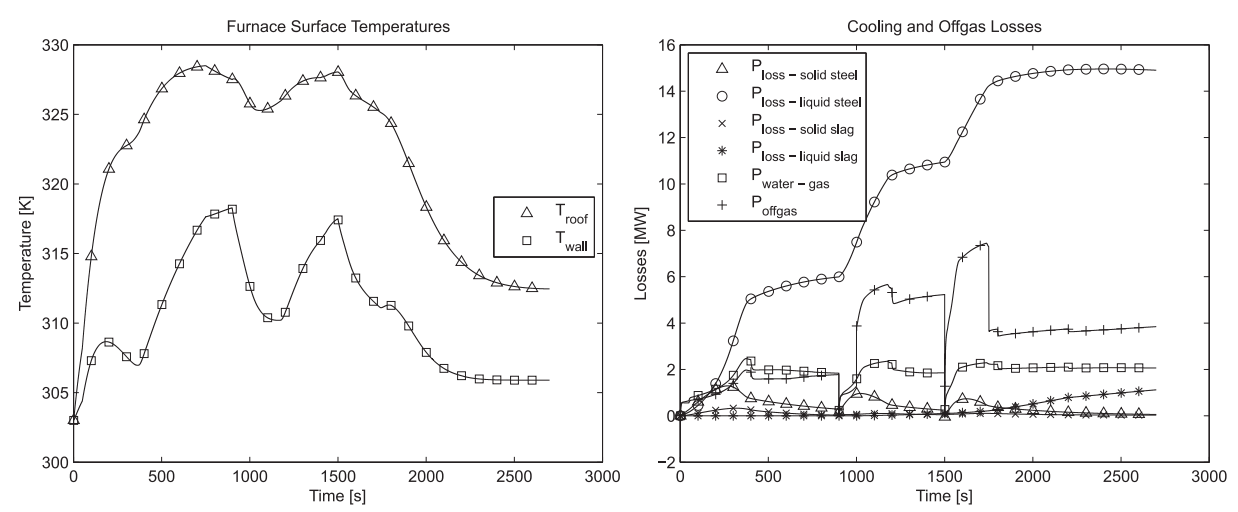

Fig. 11. Left panel: Temperatures of the roof- and wall-cooling panels; Right panel: Energy losses.
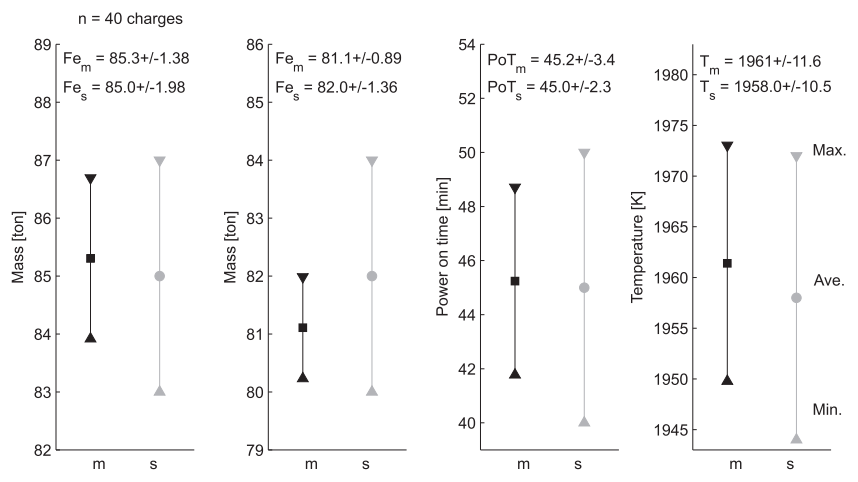

Fig. 12. Comparison between measured ( $\mathrm{m}$ ) and simulated (s) endpoint values indicating minimum (Min.), average (Ave.) and maximum (Max.) values.

Table 2. Comparison between the endpoint measured and simulated average values, including standard deviations.

\begin{tabular}{lcccc}
\hline & $\begin{array}{c}\text { Fe initial } \\
\text { [ton] }\end{array}$ & $\begin{array}{c}\text { Fe end } \\
\text { [ton] }\end{array}$ & $\begin{array}{c}\text { Power on time } \\
\text { [min] }\end{array}$ & $\begin{array}{c}\text { End steel } \\
\text { temperature }[\mathrm{K}]\end{array}$ \\
\hline Measured & $85.3 \pm 1.4$ & $81.1 \pm 0.9$ & $45.2 \pm 3.4$ & $1961.0 \pm 11.6$ \\
Simulated & $85.0 \pm 2.0$ & $82.0 \pm 1.4$ & $45.0 \pm 2.3$ & $1958.0 \pm 10.5$ \\
\hline
\end{tabular}

gas temperatures as a consequence of the oxygen burners and the oxidation of combustible materials present in the solid steel. The phenomenon is also observable in the results presented in part $2^{\text {(PART 2) }}$. Since the masses of the liquid and solid slags are lower compared to the overall charge, lower cooling powers affect the slag zones.

\subsection{Model Validation}

To further validate the developed EAF model and to ensure its applicability for the initial goals of this study, the endpoint simulation results were compared to the measured operational data and are presented in Fig. 12 and Table 2. The measured average values were obtained from the data for 40 different heats, while the simulated values were obtained from the proposed model, starting the simulation with different initial conditions. At this point a comparisons between initial and endpoint steel mass (first and second column), power on times (third column) and endpoint steel temperatures (fourth column) are given.

As can be seen in Fig. 12 and Table 2, the measured and simulated endpoint data are very similar, which indicates the accuracy of the built model and its usability for further analysis, i.e., energy optimization and an operator-training simulator. Other values, important for the validation, such as: energy consumption, endpoint steel and slag composition, are given in part 2 paper $^{\text {(PART 2) }}$ or were already presented.1)

\section{Conclusion}

In this paper an approach to the mathematical modeling and experimental validation of heat and mass transfer and the temperature profiles of the EAF processes is presented. The obtained model is mainly developed in accordance with the fundamental laws of heat and mass transfer. Parameterization of the model is carried out using available operational measurements and theoretical data for the EAF processes. Some relations had to be modeled experimentally using exponential and hyperbolic-tangent approximations as the knowledge of the process is not defined mathematically or the process exhibits non-linear behavior, which is easier to model in this manner. Regarding the presented results, the proposed model can be considered as being appropriate for the aims of the study, as high levels of similarity were achieved between the simulated results and both the theoretical and operational data available. The developed model is primarily designed for the EAF energy and cost optimization and operator-training simulator. Having a relatively accurate model of the EAF processes, different scenarios and optimization techniques can be performed to enhance the actual EAF process. The obtained model can be used for simulating any similar EAF assembly; however, the parameters need to be readjusted according to the particular operational data. Although several studies investigate the specific electric, hydraulic, mass, thermal and chemical processes of the EAF, an approach as presented in this study, which would combine all the mentioned mechanisms of those processes in a single model in this extent has not been found in the literature.

\section{Acknowledgement}

The work presented in this paper was funded by Slovenian Research Agency (ARRS) project J2-2310 Monitoring and Control of Steel Melt Quality in Electric Arc Furnace.

\section{REFERENCES}

1) V. Logar, D. Dovžan and I. Škrjanc: ISIJ Int., 51 (2011), No. 3, 382.

2) J. G. Bekker, I. K. Craig and P. C. Pistorius: ISIJ Int., 39 (1999), No. 4, 23.

3) R. D. M. MacRosty and C. L. E. Swartz: Ind. Eng. Chem. Res., 44 (2005), No. 21, 8067.

4) J. M. M. Fernández, V. Á. Cabal, V. R. Montequin and J. V. Balsera: Eng. Appl. Artif. Intell., 21 (2008), No. 7, 1001.

5) M. Kirschen, V. Velikorodov and H. Pfeifer: Energy, 31 (2006), No. $14,2926$.

6) Y. N. Toulouevski and I. Y. Zinurov: Innovation in electric arc fur- 
naces. Springer-Verlag, Berlin Heidelberg, Germany, (2010).

7) D. Guo and G. A. Irons: 3rd Int. Conf. on CFD in the Minerals Process Industries; CSIRO, Canberra, Australia, (2003), 651.

8) M. Bergman and R. Gottardi: Ironmaking Steelmaking, 17 (1990), No. 4, 282.

9) O. J. P. González, M. A. Ramírez-Argáez and A. N. Conejo: ISIJ Int., 50 (2010), No. 1, 1

10) M. R. R. I. Shamsi and S. K. Ajmani: ISIJ Int., 47 (2007), No. 3, 433.

11) R. Siegel and J. R. Howell: Thermal Radiation Heat Transfer, Taylor and Francis, Washington, USA, (2001).

12) W. Kurz and D. J. Fisher: Fundamentals of Solidification, Trans Tech Publications, Ltd., Switzerland, (2005).

13) A. Feingold: J. Heat Transf., 100 (1978), No. 4, 742.

14) M. H. N. Naraghi and B. T. F. Chung: J. Heat Transf., 104 (1982), No. 3,426 .

15) J. Alexis, M. Ramirez, G. Trapaga and P. Jönsson: ISIJ Int., 40 (2000), No. 11, 1089

16) J. A. T. Jones, B. Bowman and P. A. Lefrank: The Making, Shaping and Treating of Steel; 10th ed., Chapter 10: Electric Furnace Steelmaking, The AISE Steel Foundation, Pittsburgh, PA, USA, (1998), 525 .

17) S. Blažič, D. Matko and G. Geiger: Math. Comput. Simul., 64 (2004), 617.

18) J. G. Bekker, I. K. Craig and P. C. Pistorius: Cont. Eng. Prac., 8 (2000), No. 4, 445

19) W. Trinks, M. H. Mawhinney, R. A. Shannon and R. J. Reed: Industrial Furnaces, John Wiley \& Sons, Inc., New Jersey, USA, (2004).

20) E. T. Turkdogan: Physiochemical properties of molten slags and glasses, The Metals Society, London, UK, (1983).

21) E. T. Turkdogan: Fundamentals of Steelmaking, Institute of Materials, London, UK, (1996).

\section{Appendix}

Table 3 gives the values of all parameters used in the model including the corresponding units. Some of the values, such as: $m_{E A F}, A_{1}, A_{2}, d_{1}, d_{2}, T_{\text {water }}$ and $T_{H 2 O-i n}$ are EAF specific, while others can be obtained from different handbooks and papers studying heat-transfer processes. $K_{\text {therm }}$, $K_{\text {area } 1}, K_{\text {therm } 2}, K_{\text {area } 2}, K_{\text {therm } 3}, K_{\text {area } 3}, K_{\text {therm } 5}, K_{\text {area } 5}, K_{\text {therm } 6}$ and $K_{\text {area } 6}$ were obtained from the paper by Bekker; ${ }^{2)} \varepsilon_{1}, \varepsilon_{2}, \varepsilon_{3}$ and $\varepsilon_{4}$ were obtained from; ${ }^{19)} C_{p, s S c}, C_{p, l S c}, C_{p, s S l}, C_{p, I S l}, C_{p, g a s}$, $C_{p, H 2 O}, C_{p, \text { roof }}$ and $C_{p \text {,wall }}$ were obtained from;,20,21) $\lambda_{s S c}$ and $\lambda_{s S l}$ were obtained from, ${ }^{12)} K_{\text {therm } 4}, K_{\text {therm }} 7$ and $K_{\text {therm } 8}$ were obtained from approximate heat transfer coefficients for steel and slag ${ }^{7,9,10)}$ normalized to the specific EAF properties (dimensions), while $K_{\text {water } 1}, K_{\text {water } 2}, K_{\text {water } 3}, K_{\text {water } 4}$ and $K_{\text {water } 5}$ were obtained from approximate heat transfer coefficients for furnace walls ${ }^{7)}$ normalized to the specific EAF dimensions.

Table 3. Values of the parameters used in the model.

\begin{tabular}{|c|c|c|c|c|c|c|}
\hline$K_{\text {therml }}$ & $K_{\text {areal }}$ & $K_{\text {therm } 2}$ & $K_{\text {area } 2}$ & $K_{\text {therm } 3}$ & $K_{\text {area } 3}$ & $K_{\text {therm } 4}$ \\
\hline $0.2 \frac{\mathrm{kW}}{\mathrm{m}^{2} \mathrm{~K}}$ & $0.008 \frac{\mathrm{m}_{2}}{\mathrm{~kg}}$ & $0.2 \frac{\mathrm{kW}}{\mathrm{m}^{2} \mathrm{~K}}$ & $0.12 \frac{\mathrm{m}_{2}}{\mathrm{~kg}}$ & $0.05 \frac{\mathrm{kW}}{\mathrm{m}^{2} \mathrm{~K}}$ & $0.12 \frac{\mathrm{m}_{2}}{\mathrm{~kg}}$ & $57.5 \frac{\mathrm{kW}}{\mathrm{K}}$ \\
\hline$K_{\text {therm } 5}$ & $K_{\text {area } 5}$ & $K_{\text {therm } 6}$ & $K_{\text {area } 6}$ & $K_{\text {therm } 7}$ & $K_{\text {therm } 8}$ & $K_{\text {water } 1}$ \\
\hline $0.2 \frac{\mathrm{kW}}{\mathrm{m}^{2} \mathrm{~K}}$ & $0.12 \frac{\mathrm{m}_{2}}{\mathrm{~kg}}$ & $0.08 \frac{\mathrm{kW}}{\mathrm{m}^{2} \mathrm{~K}}$ & $0.12 \frac{\mathrm{m}_{2}}{\mathrm{~kg}}$ & $22.5 \frac{\mathrm{kW}}{\mathrm{K}}$ & $22.5 \frac{\mathrm{kW}}{\mathrm{K}}$ & $12 \frac{\mathrm{kW}}{\mathrm{K}}$ \\
\hline$K_{\text {water } 2}$ & $K_{\text {water } 3}$ & $K_{\text {water4 }}$ & $K_{\text {water } 5}$ & $T_{m e l t}$ & $T_{\text {water }}$ & $m_{E A F}$ \\
\hline $20 \frac{\mathrm{kW}}{\mathrm{K}}$ & $10 \frac{\mathrm{kW}}{\mathrm{K}}$ & $5 \frac{\mathrm{kW}}{\mathrm{K}}$ & $0.05 \frac{\mathrm{kW}}{\mathrm{K}}$ & $1809 \mathrm{~K}$ & $298 \mathrm{~K}$ & $105.000 \mathrm{~kg}$ \\
\hline$\varepsilon_{l}$ & $\varepsilon_{2}$ & $\varepsilon_{3}$ & $\varepsilon_{4}$ & $\sigma_{S B}$ & $C_{p, S S c}$ & $C_{p, l S c}$ \\
\hline 0.85 & 0.85 & 0.80 & 0.40 & $5.67 \times 10^{-8} \frac{\mathrm{J}}{\mathrm{m}^{2} \mathrm{~K}^{4} \mathrm{~s}}$ & $0.039 \frac{\mathrm{kJ}}{\mathrm{molK}}$ & $0.047 \frac{\mathrm{kJ}}{\mathrm{molK}}$ \\
\hline$C_{p, s S l}$ & $C_{p, I S l}$ & $C_{p, g a s}$ & $C_{p, \mathrm{H} 2 \mathrm{O}}$ & $T_{H 2 O-i n}$ & $A_{l}$ & $A_{2}$ \\
\hline $0.025 \frac{\mathrm{kJ}}{\mathrm{molK}}$ & $0.047 \frac{\mathrm{kJ}}{\mathrm{molK}}$ & $0.030 \frac{\mathrm{kJ}}{\mathrm{molK}}$ & $0.075 \frac{\mathrm{kJ}}{\mathrm{molK}}$ & $298 \mathrm{~K}$ & $25.5 \mathrm{~m}^{2}$ & $17.1 \mathrm{~m}^{2}$ \\
\hline$d_{l}$ & $d_{2}$ & $\rho_{\text {I\& } 2}$ & $C_{p, \text { roof }}$ & $C_{p, \text { wall }}$ & $\lambda_{s S c}$ & $\lambda_{s S l}$ \\
\hline $0.30 \mathrm{~m}$ & $0.45 \mathrm{~m}$ & $7000 \frac{\mathrm{kg}}{\mathrm{m}^{3}}$ & $0.65 \frac{\mathrm{kJ}}{\mathrm{kgK}}$ & $0.96 \frac{\mathrm{kJ}}{\mathrm{kgK}}$ & $15.4 \frac{\mathrm{kJ}}{\mathrm{mol}}$ & $12.66 \frac{\mathrm{kJ}}{\mathrm{mol}}$ \\
\hline
\end{tabular}

